Judith Butler and her methodical precariousness

\title{
Judith Butler y su precariedad metódica
}

Anisa Azaovagh de la Rosa

Universidad de La Laguna

azauagh@hotmail.com

DOI: https://doi.org/10.15366/bp2019.22.007

Bajo Palabra. II Época. № 22. Pgs: 147-170

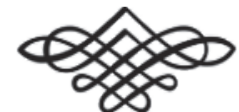


Recibido: 03/08/2018

Aprobado: 02/10/2019

\section{Resumen}

Este artículo proporciona una perspectiva metódica de la reciente obra de Judith Butler donde, como ella misma ha expresado, trata de redefinir la ética. Dada la condición precaria (abierta e inconclusa) del discurso de esta autora, que ella misma acepta y explicita desde el comienzo de su carrera, en este artículo se sostiene que cualquier acercamiento sobre la misma no puede ser de una forma "bien configurada" o de un "acabamiento coherente" a salvo de la precariedad. Esto no quiere decir que se abra la puerta a una arbitrariedad desbocada, pero si se esbozará en las próximas páginas cierto marco metódico para abordar su ética de la no violencia que, como ética aplicada, es dependiente de la ética teórica. Se apela así, a la "matriz disciplinal de la ética" cuyos elementos son: el juicio, la acción, el sujeto y los criterios morales éticos y metaéticos. Todos ellos constituyen un "sistema" que persiste más allá de los tiempos y que proporciona a la ética una identidad disciplinal exclusiva y diferenciada de otras. Finalmente, se expondrá cómo estos elementos son alcanzados por la precariedad, cuya consecuencia más inmediata es una "metaética deconstructiva" y una "ética precaria".

Palabras clave: precariedad metódica, ética aplicada, metaética deconstructiva, Judith Butler.

\section{Abstract}

This paper provides a methodical perspective of Judith Butler's recent work where, as she herself has expressed, she seeks to redefine ethics. Given the precarious (open and unfinished) condition of this female author's speech, which she herself accepts and explains from the beginning of her career, this article argues that any approach to her cannot be in a "well-configured" or "coherent finishing" way that is safe from precariousness. This does not mean that the door will be opened to unbridled arbitrariness, but it does mean that a certain methodical framework will be outlined in the following pages to approach its ethics of nonviolence, which, as applied ethics, is dependent on theoretical ethics. The "disciplinary matrix of ethics" is thus called upon, the elements of which are: judgment, action, subject and ethical and metaethical moral criteria. All of them constitute a "system" that persists beyond time and provides ethics with an exclusive and differentiated disciplinary identity. Finally, it will be explained how these elements are reached by precariousness, the most immediate consequence of which is "deconstructive metaethics" and "precarious ethics".

Keywords: methodical precariousness, applied ethics, deconstructive metaethics, Judith Butler. 


\section{El contexto general del surgimiento de la ética de Butler.}

EN sus ÚLTimos trabajos Judith ButLer ha mostrado una preocupación por la cuestión ética. ${ }^{1}$ En estos trabajos se asiste a un desplazamiento desde una interrogación acerca de las prácticas de subjetivación y el carácter performativo de las categorías de género y de sexo ${ }^{2}$ hacia una reflexión más amplia acerca de las condiciones de "inteligibilidad de lo humano". Esto es, a los problemas ontológicos y sus implicaciones éticas asociadas al reconocimiento de la vida como "humana" o a su negación. No se trata de una ruptura teórica pues Butler intenta más bien extraer las consecuencias éticas de una concepción radicalmente descentrada y abierta del sujeto y, por esa vía, replicar la idea de que la crítica - postestructuralista - de la soberanía del sujeto socavaría los fundamentos de la acción y la interpelación moral y, con ello, la noción misma de responsabilidad, y derivaría así inevitablemente en nihilismo moral. Por el contrario, Butler aspira a mostrar que esa pérdida de soberanía, en especial, a partir del reconocimiento de estar implicado constitutivamente con los demás y, por ende, en una vulnerabilidad o precariedad compartida, es la condición misma de emergencia de la interrogación moral y la responsabilidad ética y política.

Asimismo, en esta última aportación teórica expresa abiertamente que pretende repensar la esfera de la ética en un marco social contemporáneo ${ }^{3}$ en "(...) un intento de aproximación a una ética de la no violencia (...). ${ }^{4}$ Situar la ética en ese marco pone al descubierto "(...) no sólo que las cuestiones morales surgen en el contexto de relaciones sociales, sino que la forma que adoptan esas cuestiones cambian según el contexto, e incluso que éste mismo, en algún sentido, es inherente a la forma de

\footnotetext{
* Este trabajo se inserta dentro del proyecto “Justicia, ciudadanía y vulnerabilidad. Narrativas de la precariedad y enfoques interseccionales" (FFI2015-638995-C2-1-R-) del Ministerio de Economía y Competitividad del Gobierno de España.

${ }^{1}$ Me refiero a su obra más reciente como Vida precaria. El poder del duelo y la violencia, Buenos Aires, Paidós,2006; Dar cuenta de sí mismo. Violencia ética y responsabilidad, Buenos Aires, Amorrotu, 2009 y Marcos de guerra. Las vidas lloradas, Barcelona, Paidós,2010.

2 Concretamente me refiero a El género en disputa. El feminismo y la subversión de la identidad, Barcelona, Paidós, 2007; Deshacer el Género. Paidós, Barcelona, 2006; Lenguaje, poder e identidad. Síntesis, Madrid, 2004, Mecanismos psíquicos de poder, Cátedra, Madrid, 2010 y Cuerpos que importan. Sobre los límites materiales y discursivos del «sexo», Buenos Aires, Paidós, 2002.

3 Butler, J., Dar cuenta de sí mismo. Violencia ética y responsabilidad, Buenos Aires, Amorrotu, 2009, p.13.

${ }^{4}$ Butler, J., Vida precaria. El poder del duelo y la violencia, Buenos Aires, Paidós,2006, p. 20.
} 
la cuestión." 5 Esta idea de tomar en cuenta las contingencias sociales por las que se ve afectada la propia moral es dependiente de la lectura que la filósofa hace de Adorno en Dar cuenta de si mismo. ${ }^{6}$ En esta obra se hace eco de la crítica adorniana al universalismo abstracto al que el filósofo imprime un carácter violento por dejar de lado las condiciones sociales y culturales -léase también como particularidad(es)ámbito práctico de la moral y de la que ella misma surge como respuesta. Para Adorno la moral tiene su condición básica en la crisis de los preceptos brindados por una comunidad o tradición de costumbres y hábitos normativos (ethos) como la posibilidad de deliberarlos y cuestionarlos críticamente. De este modo, la ética ${ }^{7}$ no puede desligarse de las condiciones sociales, "(...) que son también las condiciones en que sería posible apropiarse de cualquier ética (...).” En la misma línea que Adorno, Butler considera que si el ethos, con sus preceptos pretendidamente universales, se nos impusieran sin atender a las estructuras sociales y políticas por las que se hace posible una "apropiación vital" por parte de los sujetos se revelaría como violencia.

Así pues, haciéndose eco de lo que Adorno consideraba el problema central de la filosofía moral - la relación entre lo particular y lo general en referencia a "si es posible una vida recta aun en un medio falso" " - la teoría ética de Butler estará avocada dar respuesta al marco social contemporáneo. ${ }^{10}$ Un marco caracterizado por un ambiente guerras, especialmente las estadounidenses llevadas a cabo durante la legislatura de G. Bush contra países orientales, tal como nos expone al comienzo de su obra Vida Precaria y, en la obra que estima como su continuidad, Marcos de Guerra. De modo que, Butler, articulará lo que podemos denominar su "ética de la no violencia" como respuesta a la política belicista estadounidense, sobre todo, a partir de los atentados del 11 de septiembre de 2001 y dadas las subsiguientes condiciones de incremento de la vulnerabilidad y de la violencia.

\footnotetext{
5 Butler, J., Dar cuenta de sí mismo, op.cit., p.13.

${ }^{6}$ Concretamente de los textos Adorno, T.W. Problems of Moral Philosophy. Trad. Rodney Livingstone, Stanford, Stanford University Prees, 2001. (citado por Butler), Minima moralia. Taurus, Madrid, 1984 y Dialéctica de la ilustración. Madrid, Akal, 2007.

7 Como bien señala Butler, Adorno utiliza de manera diferenciada el término moral y ética, decantándose por el primero para su proyecto teórico y refiriéndose al segundo para los perfiles generales de esas reglas y máximas. No es el caso de Butler, para quién la ética constituirá su proyecto teórico. Butler, J., Dar cuenta de sí mismo, op. cit., p. 16.

8 Ídem.

9 Adorno, T., Minima moralia, op. cit., p. 251.

${ }_{10}$ Si sociológicamente la apuesta Butleriana por la no violencia está relacionada con la guerra de Irak acontecida en 2003, de cuya realidad surge su preocupación ética, conceptualmente lo está con las éticas de la paz encabezadas por filósofos como Kant en su propuesta de un humanismo cosmopolita, como también con Enmanuel Levinas, un precursor de la paz como valor ético. Véase González Rodríguez Anáiz, G., Interculturalidad y convivencia. El "giro intercultural" de la filosofía, Madrid, Biblioteca Nueva,2008, pp. 181-209.
} 
Después del 11 de septiembre de 2001, nos dice Butler, por primera vez Estados Unidos se halla en un momento de impasse en el que se hace visible su propia vulnerabilidad, fragilidad y dependencia frente a la imagen tradicional mediante la que se había vendido como frontera impermeable a la vulnerabilidad. Una imagen que, como señala la filósofa, ha formado parte de la posibilidad de hacer y seguir haciendo la guerra indiscriminadamente a los países islámicos. Aunque ese momento teñido de destrucción, muerte y dolor, nos dice Butler, pudo ser propicio para que Estados Unidos optara por una nueva política que tomara en cuenta la vulnerabilidad y la interdependencia propia de toda nación, no fue así. Estados Unidos optó por considerarse un Estado sin porosidades y reforzó aún más su soberanía generando aún más violencia militar y represalia. De este modo, hay una creciente censura de los medios de comunicación y un antiintelectualismo generalizado que no puede presentar un discurso crítico que revele cómo la política exterior de Estados Unidos ha contribuido a los atentados del 11 de septiembre de 2001. Y, mucho menos, elaborar una respuesta ético-política a la destrucción y la violencia que no genere aún más destrucción y más violencia. En este sentido, se produce una conjura entre los medios de comunicación y el Estado belicista, ya que aquéllos más que generar una representación crítica de la guerra que, posteriormente, en el 2003 se declara contra Afganistán, forman parte del "hacer la guerra", es decir, se vuelven, en palabras de Butler, "instrumentos materiales" 11 de la guerra y la violencia al producirse una identificación con la perspectiva belicista del gobierno.

A partir de esa conjura, la cobertura mediática de la guerra a través de una interpretación normativa que trataba de legitimarla dirigió la afectividad y comprensión pública de la misma, de modo que se hizo difícil una oposición política. Los otros, a los que se la había declarado, ya habían sido deshumanizados a través de los medios de comunicación, principales transmisores de una normatividad moral de lo humano, por lo que se convirtieron en carne de cañón como pretexto para proteger mejor la vida de los «verdaderamente humanos». Así, las iconografías y discursos a través de su circulación o de su ocultamiento constituyeron procedimientos de la retórica pública que produjeron una ideologización ética diferencial que favoreció la aceptación y legitimación pública de la guerra: los otros eran demonizados como encarnación del mal absoluto, la barbarie y el fanatismo (árabe-islámico), mientras los estadounidenses eran definidos por su opuesto axiológico el bien infinito, la civilización y la racionalidad. ${ }^{12}$ Se presenta así un marco en el que es mucho más

${ }_{11}$ Butler, J., Violencia de Estado, guerra, resistencia. Por una nueva politica de izquierda, Madrid, Katz, 2011, p. 10.

12 El País publicó un ejemplo de esta dicotomía maniquea. Este periódico retrató a Sadam Husein destacando sus rasgos físicos, que, junto con otros detalles como su matrimonio, evocaban prejuicios étnicos, en oposición se retrataba al presidente G. Bush enfatizando su cualificación académica. (17-1-1991:6). 
hacedera la guerra porque las vidas que son objeto de destrucción y violencia son transmutadas representacionalmente en vidas que no merecen estar vivas, aunque lo estén y, por tanto, no pueden percibirse como preciadas de ser lloradas. Esta deshumanización del otro y de la guerra ${ }^{13}$ sofocó la crítica y el debate intelectual y social en el contexto de la crítica al Estado norteamericano y su violencia militar a la par que aseguro su legitimación.

\section{La obra de Judith Butler y su precariedad metódica.}

AHORA BIEN, ¿CÓMO ABORDAR metódicamente, en un marco teórico más o menos adecuado, la densa y compleja problemática anterior? La profesora Elvira Burgos inicia su importante investigación sobre la obra de Butler, refiriéndose a ella como un pensamiento innovador y sobresaliente en el panorama internacional y, a la hora de justificar estas manifestaciones elogiosas, resalta por encima de cualquier otra su significación crítica. ${ }^{14}$ A continuación caracteriza la crítica como política pese a que se trate de una obra filosófica, por eso considera que el estilo de escritura de Butler es "una estrategia política" 15 antes que epistemológica. En su opinión, Butler examina los problemas más acuciantes del mundo contemporáneo de un modo muy personal: afronta el "análisis de textos difíciles cuyos significados no son directamente accesibles." "Esta dificultad - prosigue - es la que puede generar en la persona que lee una actitud crítica hacia el mundo social y su habitual constitución”. ${ }^{16}$ Esta actitud se radicaliza por el hecho de que el pensamiento de Butler "ofrece preguntas antes que definitivas respuestas para incitar la mirada penetrante capaz de escrutar con ojos múltiples lo que se nos dice sobre la realidad dada." ${ }^{17}$ Por último - pero no menos importante - la actitud crítica recibe otra vuelta de tuerca cuando Elvira Burgos se refiere a que la propia Butler reconoce que "su escritura puede parecer impenetrable" lo cual justificaría que haya sido considerada "sofis-

\footnotetext{
${ }_{13}$ Véase Martin Rojo, L., "El campo de batalla de los discursos. Discursos e imágenes en torno a la ocupación de Irak" en Roldán, C., Ausín, T., Mate, R., (eds.), Guerra y Paz en nombre de la politica. Madrid, Calamar, 2004. Luisa Martín analiza magistralmente cómo se fue desarrollando control de los discursos y como emergieron nuevas formas de resistencia en la Guerra del Golfo (1991) y en la de Irak (2003). Allí, la autora se refiere a "guerra deshumanizada" para referirse a como líderes políticos implicados en la guerra de Irak como Bush o Aznar en nuestro país se referían a la guerra como "guerra no cruenta" o "guerra inteligente" ..., en una selección léxica nada inocente que trataba de dar una interpretación de la guerra que restara en connotaciones violentas, tratando de persuadir a la opinión pública de que esa guerra dańaría lo menos posible.

${ }_{14}$ Burgos, E., Qué cuenta como una vida. La pregunta por la libertad en Judith Butler, Madrid, Mínimo tránsito, 2008, p. 13

${ }^{15}$ Ibid., p. 14

${ }^{16}$ Ídem.

17 Ibid., pp.13-14. La cursiva es mía.
} 
ticada y oscura, signo de elitismo". A lo cual responde que "su estilo (...) pone en cuestión nuestras nociones de lo que es y no es inteligible con el fin de extender los horizontes lingüísticos y epistemológicos. " ${ }^{18}$ Coherente con estos rasgos metódicos que aprecia en la obra de Butler, Elvira Burgos concluye que "no pretende mostrar algo así como "lo definitivo" (...) de una obra compuesta por múltiples y variadas identificaciones teóricas." 19

En la introducción del libro de Elvira Burgos hay una segunda dimensión: la explicación del contenido significativo de la crítica política que, según ella, encarna el estilo de escritura de Butler. Ese contenido consiste en los efectos que produce, lo cual la sitúa en el marco de la pragmática lingüística. ${ }^{20} \mathrm{El}$ efecto final y más visible es, como ya se ha aclarado, político: la modificación de la actitud acrítica de las lectoras/es. Pero este efecto tiene que ver con otros más sutiles, de condición filosófica. El primero de ellos es "el cuestionamiento de lo que es y no es inteligible" lo cual implica "extender los horizontes lingüísticos y epistemológicos" de las lectoras/res. Con lo cual Elvira Burgos nos está diciendo que la inteligibilidad tiene lugar en esos términos: lingüísticos y epistemológicos. Lo primero tiene que ver, obviamente, con el lenguaje y sus usos y lo segundo con los conceptos y su lógica.

Sobre la dimensión lingüística Elvira Burgos atribuye a Butler la idea de que la inteligibilidad común, que constituye la urdimbre del "mundo ordinario", está estructurada y normalizada por el "lenguaje ordinario"; pero que este "orden normal" o "normalidad ordinaria" puede ser alterado mediante un lenguaje filosófico dificil. También le atribuye el aprendizaje, a partir de la lectura de Hegel y Heidegger, de que "la dificultad del lenguaje era un camino esencial para el pensamiento filosófico" y que "lo comúnmente aceptado, nuestros presupuestos asentados, son susceptibles de ser modificados a través de la gramática y el estilo." El "mundo ordinario" puede ser discutido "en su pretensión de ser un verdadero indicador de la realidad como ella es y cómo tiene que ser", y esa discusión nos invita a considerar "cómo lo nuevo puede ser incorporado a nuestro mundo." ${ }^{21}$

Por su parte, los efectos sobre el lenguaje ordinario producen otros en los significados y conceptos implicados, algunos "tan importantes como los de "persona", "sujeto", "identidad de género" o "sexualidad". E inmediatamente Elvira Burgos considera esta cadena de efectualidad lingüística y lógica como una "tarea de apertura hacia lo nuevo", que no debe quedar en mero cuestionamiento de un léxico o

\footnotetext{
${ }_{18}$ Ibid., p.14.

19 Ibid., p.16.

${ }^{20}$ Sobre estas diversas dimensiones del lenguaje, desde la perspectiva del fundador del pragmatismo, Peirce, Ch. S., ver Bello Reguera, G., "Pragmática, hermenéutica y ética de la alteridad", en Ońate, T., y otros (Eds), Crítica y crisis de Occidente. Al encuentro de las interpretaciones, Madrid, Dykinson, S.L., 2013, p. 57.

21 Burgos, E., Qué cuenta como una vida. La pregunta por la libertad en Judith Butler, op. cit., p. 14.
} 
de una estructura conceptual, sino que debe producir un sentido inédito de "lo que el mundo es". Pero cuidando de abstenerse de creer que lo nuevo es o puede ser "lo definitivo". ${ }^{22}$ La apertura hacia lo nuevo nunca acaba o debe acabar en un cierre terminal. Esta propuesta puede llevar a "la suspensión de las seguridades ontológicas y epistemológicas, pero [...] puede dotarnos de una mayor capacidad para el entendimiento de las diferencias." ${ }^{23}$

En coherencia con su interpretación y valoración de la apertura (a lo nuevo y diferente) como uno de los ingredientes metódicos de la obra de Butler, Elvira Burgos presenta su propio trabajo sobre ella como un "concreto y limitado ejercicio de escritura sobre una producción teórica que siendo ya extensa promete continuar ampliando su potencial creativo." ${ }^{4}$

Una apreciación similar de la apertura en la obra de Butler puede encontrarse en María Luisa Femenías al escribir que "es propio de los textos de Butler admitir diversas interpretaciones, incluso en conflicto", con lo cual, por otro lado, disuelve el problema de "cuál es la interpretación de la obra de Butler". Considera que su texto está abierto y que su autora

"solo da razón precaria, provisoria, nunca sintética de los nudos problemáticos que la invitaron a la reflexión (...) nunca podremos llegar a una lectura última de sus obras. Nunca podremos alcanzar su "origen" (Nietzsche) ni llegar a un término absoluto (Hegel). Para Butler no hay un orden teleológico que indique un punto de llegada y, consecuentemente, de partida." 25

En este texto María Luisa Femenías afirma la inexistencia del método teleológico de inteligibilidad tanto en las obras de Butler como en los problemas que aborda en ellas: no se llega ni a un significado último ni se parte de un origen determinable. No hay, pues, un espacio teórico sistemático en el que se puedan situar los problemas de forma clara y ordenada. Todo queda en una situación provisoria o provisional a la que identifica como precaria. Coherente con esta visión Femenías cierra su propio trabajo con un epígrafe titulado "conclusiones precarias." 26

Tanto Elvira Burgos como María Luisa Femenías se cuidan de llamar la atención sobre la condición inacabada y abierta de la obra de Butler. Y las dos coinciden, consecuentemente, en reconocer esos mismos rasgos - apertura e inacabamiento en sus propias investigaciones sobre esa obra. Femenías, sin embargo, da un paso

\footnotetext{
${ }^{22}$ Ibid., p. 16 .

23 Ibid., p.17.

${ }^{24}$ Ibid., p. 18

25 Femenías, M. L., «Butler, la muerte del hombre y el sujeto opaco >>. Revista de Psicoanálisis». En revista Psicoanalisis, Tomo LXXI, no 2/3, Argentina, 2013, p. 356. La cursiva es mía.

26 Ibid., p. 368.
} 
más al usar dos veces el término "precariedad", que yo he subrayado, una para referirse a la "razón" que Butler da de los problemas que aborda y otro para calificar sus propias conclusiones. De este modo, aplica a la obra de Butler la categoría que esa misma obra atribuye a la vida humana: la precariedad. Tanto la obra de Butler como el trabajo de Femenías sobre ella (o el de E. Burgos) son distintas expresiones de la vida humana y, por lo tanto, de su precariedad. Butler representa la vida humana como precaria y Femenías extiende la precariedad a la representación de Butler de esa vida, así como a su propio trabajo sobre ella. De este modo, la precariedad se desdobla en perspectivas interrelacionadas o interdependientes. Para Butler, la precariedad humana es el objeto o tema de su investigación filosófica, mientras que para Femenías, la precariedad forma parte de esa investigación y su método: la escritura filosófica.

\section{Un marco teórico precarioł la ética aplicada.}

Como investigadora de la obra de Butler, me gustaría situarme en el marco abierto por ambas filosofas, Elvira Burgos y María Luisa Femenías. Si recordamos la significación política que Elvira Burgos atribuye a la escritura de Butler, resulta que la precariedad como método forma parte de su estrategia política. En el contexto de guerra y violencia en el que se mueve la última Butler, la precariedad se revela como el valor o el criterio axiológico que permite criticar las políticas de la violencia y, a la vez, inspirar una ética de la no violencia y sus correspondientes políticas. ${ }^{27}$

Desde esta perspectiva se explica no sólo la apertura y el inacabamiento de la obra de Butler, sino también su aparente desorden o ausencia de sistematicidad que caracteriza, por ejemplo, su trabajo reciente sobre la violencia, el terrorismo y la guerra, disperso en ensayos altamente densos pero que no están integrados en un orden sistemático. ${ }^{28}$ Me refiero, claro está, a los dos volúmenes titulados, respectivamente, Vida precaria y Marcos de Guerra. Y cuando un cierto orden se hace visible en el índice de un libro como Dar cuenta de uno mismo, su escritura parece concebida más para ocultarlo que para exponerlo. Lo que quiere decir que, cualquier trabajo sobre su obra no puede aspirar a ser cerrado y bien terminado, con un origen y un final bien definidos y un trascurso argumental coherente entre ambos, porque la última obra de Butler, donde tarta de articular una ética de la no violencia, no es una totalidad cerrada en sí misma, de la que haya que dar cuenta

\footnotetext{
${ }^{27}$ Lo primero en "Violencia, duelo, política" y lo segundo en "Vidas precarias", ambos recogidos en el volumen Vida precaria, op. cit.

28 Me refiero, claro está, a los volúmenes Vida precaria y Marcos de Guerra, op. cit.
} 
en términos de ese mismo criterio: el de totalidad cerrada. No hay un orden que reproducir, sintetizar o condensar. Dicho de otra manera, lo único que se puede reproducir o repetir es su apertura y su inacabamiento: su precariedad. Ello, por otro lado, tiene la ventaja de permitir abrir la investigación a elementos que contribuyan a enriquecer su contenido o reforzar su inteligibilidad, sean internos a la obra de la propia Butler como, por ejemplo, los trabajos de su primera época ${ }^{29}$, o externos a ella como los autores y autoras a los que ha recurrido antes o ahora.

Ahora bien, si cualquier trabajo sobre está reciente obra de Butler, ha de presentar un mínimo de coherencia interna, que lo identifique como reconocible y, a la vez, como diferenciable de otros, es imprescindible dotarlo de un marco teórico en el que sea posible situar los problemas abordados dentro de cierto orden. Siempre en el horizonte de la apertura y la precariedad metódicas. Con esta intención he creído conveniente recurrir a un marco que sea capaz de integrar la aproximación de Butler a lo que ella presenta como "el esbozo de un proyecto de una ética judía de la violencia" que viene a ser una parte de su intensa y extensa crítica de la violencia. ${ }^{30}$ Una crítica que se despliega en su doble sentido: como la valoración negativa que la rechaza y como valoración positiva de su opuesto, la no violencia, que permite "imaginar un mundo en el que la violencia pueda minimizarse." 31 Teniendo en cuenta que estas dos valoraciones son, en realidad, juicios morales o éticos no es difícil concluir que su marco es el de la ética aplicada - a la violencia en este caso - diferenciada de la ética teórica o filosófica. Ahora bien, dada la amplia y variada "aplicación" de la ética aplicada - valga la redundancia - a los problemas más diversos, tanto de modo formal o académico ${ }^{32}$ como informal o mediático, su marco general no suele llamar especialmente la atención ya que, además, el pluralismo democrático no cuestiona la ética que cada uno aplica en sus juicios morales.

A pesar de ello conviene visibilizar los rasgos o elementos básicos que la caracterizan. Comenzando por aclarar que, en el caso de Butler, se trata de una ética aplicada a la política terrorista y contraterrorista, y no de su reducción bioética a los "problemas hospitalarios" del nacimiento/aborto, la muerte/eutanasia y la salud de mayor o menor calidad. ${ }^{33}$ Después, es imprescindible insistir en que la ética aplicada en general y la de Butler en particular constituyen una trama conceptual propia y

${ }_{29}$ Ver, en este sentido, los trabajos de Burgos, E., Qué cuenta como una vida. La pregunta por la libertad en Judith Butler, op. cit., y Pérez Navarro, P., Del texto al sexo Judith Butler y la performatividad op. cit.

${ }^{30}$ Butler, Judith. Vida precaria, op. cit., p. $166 .$.

${ }^{31}$ Ibid., p.14.

$32 \mathrm{Al}$ respecto puede verse, Cortina, A., Ética aplicada y democracia radical, Madrid, Tecnos, 1993. Este libro es sólo un ejemplo de las muchas publicaciones sobre ética aplicada, así como aplicaciones de la ética a los temas más diversos. La misma Adela Cortina junto con Victoria Camps han sido protagonistas de muchas de ellas.

${ }^{33}$ Hay quien, como Teresa López de la Vieja, es muy consciente de que la bioética forma parte de una biopolítica que tiende a quedar en la sombra, pero que es decisiva en su génesis: La pendiente resbaladiza. La práctica de la 
específica de la ética, que la define como tal y la diferencia de otras. Quizá análogas y solapadas con ella, pero diferentes unas de otras como la Política, la Filosofía del Lenguaje y la Comunicación, la Sociología o la Biología, por nombrar algunas con las que se relaciona la ética de Butler de forma más o menos explícita. ${ }^{34}$ Para identificar y diferenciar la ética sería necesario situarla en su marco más o menos tradicional que, más allá de sus diferencias internas (aristotélica, kantiana, utilitarista, etc.), se ha trasmitido de generación en generación y analizar los elementos que lo integran, cuyo conjunto daría lugar a lo que algunos denominan "maquinaria teórica tradicional" y otros matriz teórica de la ética. ${ }^{35}$

Para una aproximación a los elementos de esta matriz teórica, que se pone en juego en la ética aplicada, hay un procedimiento relativamente sencillo: interrogar a la propia actividad de valorar críticamente en sentido positivo o negativo. ${ }^{36} \mathrm{El}$ primer elemento que aparece es el juicio moral o ético, expresión de dicha valoración crítica, ya se trate de un juicio moral explícito y formal del tipo "X es bueno, justo, etc.", o su contrario, sea cual sea su cualificación positiva o negativa. $\mathrm{O}$ bien de un juicio implícito o informal bajo la modalidad de un adjetivo emotivo (o usado emotivamente) como "terrorista", "islamista", "oriental", "yihadista", "occidental", "imperialista", "emigrante", "ilegal", "autóctono", etc. ${ }^{37} \mathrm{O}$, finalmente, de expresiones valorativas en sí mismas, como "violencia legítima" o "violencia ilegítima", por incluir un adjetivo valorativo. Es preciso insistir en que dicho juicio es ético y no (o no sólo) político, estético o jurídico y eso implica una diferencia ya que, en caso contrario, el término "ética" carecería de significado. Cabe la posibilidad de que el juicio tenga, a la vez, un significado político y ético ${ }^{38}$ pero, aun así, si se ha de seguir hablando de ética y política como actividades diferentes, o de crítica ética de la política, debe mantenerse la diferencia entre ambas. En caso contrario, el lenguaje en el que son usadas esas palabras carecería de significado.

argumentación moral, Madrid, Plaza y Valdés, 2010, capítulo 7, titulado, precisamente, "Bioética y biopolítica."

34 Sobre la diferencia y la relación entre la ética y algunas de estas disciplinas, Gómez, C. y Muguerza, Javier, (eds.), La aventura de la moralidad. Paradigmas, fronteras y problemas de la ética, Madrid, Alianza Universidad, 2007.

35 La primera de estas dos expresiones aparece en Cavarero, A., Horrorismo: Nombrando la violencia contemporánea, Barcelona, Anthopos, 2009, p. 11. La autora se refiere a la política, pero qué duda cabe que la ética también dispondría de su propia "maquinaria teórica tradicional”. La segunda expresión en Bello Reguera, G., "¿Ética filosófica o ciencia del bien y del mal? La matriz Aranguren y otras claves de la filosofía española”, en revista Claves de la razón práctica, no 197, Madrid, 2009.

36 Sobre la estructura de la aplicación como tal puede verse Conill, J., "El carácter hermenéutico y deliberativo de las éticas aplicadas”. en Cortina, A. y García Marzá, D., (Eds.), Razón pública y éticas aplicadas. Los caminos de la razón práctica en una sociedad pluralista. Madrid, Tecnos, 2003.

37 Sobre el componente emotivo del lenguaje moral, ver Stevenson, Ch., Ética y lenguaje, Buenos Aires, Paidós, 1971, cap. III, "Algunos Aspectos Pragmáticos del Significado" (sic).

38 Sería el caso, por ejemplo, de la noción de "juicio" de Arendt, H., del que puede verse una versión resumida en Guerra Palmero, M.J., Mujer, identidad y reconocimiento. Instituto Canario de la Mujer, Santa Cruz de Tenerife, 1998. 
En segundo lugar, para que un juicio moral explícito o implícito sea posible, es necesaria la concurrencia de otros elementos como, por ejemplo, el objeto al que se aplica el juicio o enjuiciamiento moral: la acción o conducta humana. Que, en el caso de Butler, es especialmente visible y relevante ya que se trata de la violencia terrorista y, sobre todo, la contraterrorista, militarista y patriótica, que se pone en juego el 11 de septiembre de 2001 y que, desde entonces, ha sido hipermediatizada e hiperinterpretada. ${ }^{39}$ La violencia no es juzgada, aquí, como una entidad abstracta, tal como sugiere el sustantivo que la nombra sino como una actividad o práctica política, ejecutada por la técnica militar, cuyas consecuencias afectan a muchas vidas humanas a las que convierte en pérdidas y lloradas (o no), las de los muertos, y doloridas o dolientes, las de los supervivientes. El juicio moral, además, se hace extensivo a los responsables políticos de la decisión, ejecución y justificación de la violencia y, por lo tanto, de la pérdida y el dolor causado a las vidas humanas afectadas. Todo esto es susceptible de enjuiciamientos críticos diversos en el contexto del pluralismo democrático. Por eso, también forman parte del objeto de la ética aplicada de Butler, otros juicios sobre los mismos acontecimientos producidos el mismo contexto en el que tienen lugar los suyos: el de opinión pública y cultura norteamericana. ${ }^{40}$ Sobre todo, la opinión de ciertos medios especialmente influyentes como el New York Times cuya complicidad con los responsables de la guerra se materializa en su comunicación icónica, mediante la publicación de imágenes de personajes occidentales y orientales como símbolos de humanidad e inhumanidad. ${ }^{41}$ Por eso Butler mantiene que los medios de comunicación y las imágenes mismas, forman parte del material de guerra al lado de otras tecnologías especializadas en la producción de muerte y destrucción. ${ }^{42}$

En este punto entra en juego un tercer elemento de la ética aplicada: el sujeto humano. Una acción o comportamiento que, como los violentos, debe ser enjuiciado en términos morales, no tiene lugar como un acontecimiento natural, que sólo puede ser abordado en términos científicos, mediante juicios de hecho descriptivos o explicativos, y no en términos de juicios de valor. La acción y el comportamiento violentos sólo acontecen si han sido decididos y realizados por un sujeto humano, individual o grupal entre o ante otros sujetos humanos. Vistas, así las cosas, es conveniente diferenciar la categoría de sujeto en tres modalidades. La primera es el

\footnotetext{
39 La información más exhaustiva que conozco sobre todo ello, a partir de fuentes norteamericanas diversificadas, es el libro de Bocardo Crespo, E., La politica del negocio. Cómo la administración Bush vendió la guerra de Irak, Barcelona, Horsori, 2012.

${ }^{40}$ A eso está dedicado en ensayo "Explicación y absolución, o lo que podemos escuchar", que forma parte de Butler, J., Vida precaria, op. cit.

${ }^{41}$ Ibid. 177 y ss.

42 Butler, Judith. Violencia de Estado, guerra, resistencia. Por una nueva política de izquierdas, op. cit., p.10.
} 
sujeto agente, el que decide de forma consciente, libre y responsable poner en práctica o ejecutar la acción o comportamiento violento, objeto del juicio. En el caso que nos ocupa se trataría de Bin Laden de un lado y del presidente Bush del otro - con sus respectivos entornos: políticos, económicos, mediáticos y culturales-. La segunda es el sujeto paciente, las víctimas de esa misma violencia: norteamericanas, afganas, iraquíes (o de cualquier otro lugar del planeta). Y la tercera es el sujeto indiferente, que ni es agente ni paciente, pero sí observador, testigo y juez, como la propia Butler, otros muchos intelectuales y periodistas y la opinión pública norteamericana y global.

Los dos últimos elementos de la ética aplicada - la acción o comportamiento, con sus consecuencias, y los sujetos implicados - son imprescindibles para que puedan darse juicios éticos, pero también lo son para los juicios políticos y jurídicos y las valoraciones mediáticas. Debe haber, por tanto, algún otro elemento capaz de introducir la diferencia entre unos y ese es el criterio o los criterios que permiten distinguir el tipo de juicio de que se trata. En el caso de un juicio jurídico este criterio son las leyes o normas jurídicas en vigor aplicadas por un sistema estatal complejo pero eficaz (aunque no tanto como se espera de él). En el caso del juicio moral, sin embargo, hay que comenzar por distinguir entre criterios éticos y metaéticos. Los primeros se usan en los juicios que evalúan directamente la conducta moral. Se trata de normas, códigos y costumbres como la Ley Mosaica (los diez mandamientos), la Sharia o los derechos humanos y de ideales o valores como la justicia, la bondad, la solidaridad, la libertad, la igualdad, etc. Los segundos, en cambio, se sitúan en un plano superior al de los juicios morales - de ahí el prefijo "meta", "más allá de..." - con el fin de argumentar sobre su aceptabilidad o inaceptabilidad, en términos de racionalidad, verdad, objetividad, etc., o de fe religiosa, que propician juicios metaéticos sobre la validez y aceptabilidad (o sus contrarios) de juicios morales opuestos sobre unas mismas acciones. Por ejemplo, los que se hacen sobre la violencia desde un lado u otro, y de sus perpetradores o el de sus víctimas ${ }^{43}$. Finalmente, dentro de los criterios metaéticos aún habría que distinguir entre aquellos que dan lugar a una metaética constructiva o reconstructiva de la categoría de validez universal, y aquellos otros que propician una metaética deconstructiva de esa misma categoría. En lo cual se comprometen nociones filosóficas como la intuición metafísica, la verdad o la racionalidad y, sobre todo, su incidencia en el significado del lenguaje moral. ${ }^{44}$

${ }^{43}$ Ver, por ejemplo, Bello Reguera, G., "Política del valor intercultural", en El valor de los otros. Más allá de la violencia intercultural, Madrid, Biblioteca Nueva, 2006.

44 Sobre la problemática metaética ver Bello Reguera, G., "Jacques Derrida. Metaética deconstructiva y ética de la hospitalidad”, en Fernández Agis, D. y Sierra González, A., (eds.), Aproximaciones a la filosofía francesa contem- 
En el caso de Butler la ética que ella aplica en sus juicios morales sobre la violencia es, en principio, problemática o precaria. En su contribución a un volumen colectivo dedicado a "el retorno a la ética" que, supuestamente, estaría teniendo lugar en diversas disciplinas en torno al cambio de siglo, Butler se expresa en estos términos:

"Yo no tengo mucho que decir sobre por qué hay un retorno a la ética en los años recientes, si es que lo hay, a no ser para confesar que yo me he resistido a este retorno en lo que he podido, y que lo que yo tengo que ofrecer es algo parecido a un mapa de esta resistencia y su eliminación parcial que espero sea útil para otros propósitos además de los biográficos. Me ha preocupado que el retorno a la ética haya significado un abandono de la política, y también que haya propiciado cierto refuerzo del moralismo eso me ha hecho gritar, como gritaba Nietzsche sobre Hegel, "'Aire viciado! jAire viciado! Supongo que buscar un espacio en el que respirar no es la más alta aspiración ética (...)”. ${ }^{45}$

A partir de este sarcasmo un tanto brutal dedicado a la ética, Butler, cumpliendo con su contribución a su "retorno", cuenta que su relación con ella comenzó en el contexto de su educación judía en la que hubo de enfrentarse a los dilemas morales planteados por la exterminación masiva de judíos durante la Segunda Guerra Mundial, incluidos miembros de su propia familia. Fue su primera confrontación de la ética con la violencia. Después relata un encuentro temprano con el Nietzsche de Más allá del bien y del mal en una clase de Paul de Man, a la que asiste por sugerencia de un amigo que, según dice, le habría resultado, a la vez, atractiva y repelente. Y sigue dando cuenta de la lectura, desde los catorce ańos, de una serie de pensadores judíos que incluye a Maimónides, Spinoza, Buber, Benjamin, Arendt y Scholem. Y, en especial, la obra y las cartas de Kafka cuyos dilemas morales dice haberle impresionado como "poco menos que sublimes." ${ }^{46}$ A lo cual añade que, siendo honesta, debe reconocer saber más de todos ellos que de cualquier tema escrito hoy en términos de la teoría queer. ${ }^{47}$ Un poco después vendría la lectura de Levinas en De otro modo que ser o más allá de la esencia ${ }^{48}$, al que presenta en contraste con el Nietzsche de Sobre la genealogía de la moral. La culpa - que Nietzsche resalta - como relación de autocastigo, de violencia de uno mismo contra uno mis-

poránea. Deleuze, Foucault, Derrida y Beauvoir, Barcelona, Laertes, 2007.

45 Butler, J., "Ethical ambivalence", en Garber, M., Hassen B. y Walkowitz, R., (Eds). The Turn to Ethics, Nueva York, Routledge, 2000, p. 15. La Traducción es mía. Quizá sea útil señalar que esta publicación tiene lugar un ańo antes de los acontecimientos terroristas del 11-S de 2001, cuya influencia en la ética de Butler habría de ser decisiva.

${ }^{46}$ Ibid., p. 17.

47 Ídem. En mi opinión, en este caso hay que ver la explicación de que Butler se interese por una ética de violencia "judía" y no general.

${ }^{48}$ Levinas, E., Totalidad e infinito. Ensayo sobre la exterioridad, Salamanca, Sígueme, 2001. 
mo, como mala conciencia, es, en realidad, la interiorización del implacable castigo de la Ley (el Otro) sobre uno mismo. Esta violencia interiorizada contrasta con la responsabilidad levinasiana de uno mismo para con el otro que, todo sea dicho, Butler encuentra un poco exagerada. ${ }^{49}$

Este relato autobiográfico es una muestra de la precariedad de su relación con la ética. Precariedad que - a falta de un criterio propio - hay que entender como dependencia de los autores mencionados que, al ser varios y diversos, en el texto de Butler resultan interdependendientes entre sí y con el propio texto. Y en esta interdependencia es posible incluir a otros a los que recurrirá más tarde como Adorno y otros y otras que, con la excepción de Foucault, han tenido poco que ver con la ética en el sentido formal del término, como la politóloga Adriana Cavarero o el psicoanalista J. Laplanche. ${ }^{50} \mathrm{Y}$ retoma a Hegel y su categoría de reconocimiento que, en este contexto, es recuperado como una categoría ética y ya no sólo histórico-política. ${ }^{51}$

Todo esto puede explicar que el valor que actúa como criterio de los juicios morales de Butler es, nada casualmente, la precariedad, término que sustituye con bastante frecuencia por el de vulnerabilidad, que ella toma de la ética de la alteridad de Levinas. ${ }^{52}$ Ambas son categorías complejas y requerirán más de una aclaración, pero en el presente artículo me limitaré a aclarar que hoy están en el centro de la escena socio-económica o socio-política, como precariedad económico-laboral y cultural o identitaria, debido al desplazamiento de mucha gente de su lugar de origen. Ello explica que sean, también, objeto de intereses intelectuales diversos ${ }^{53}$ como el de la propia Butler cuyo marco general es la vulnerabilidad humana que puede ser analizada en tres dimensiones o niveles.

El primero es la vulnerabilidad biológica o corporal: el cuerpo puede ser herido, dañado y muerto. Vulnerabilidad, pues, como mortalidad o pérdida de la vida humana, lo cual enmarca a esa vida en el centro de la cuestión. ${ }^{54}$ Precisamente por eso, porque lo humano está en el centro de la cuestión, la vulnerabilidad biológica no es pura o no se da en estado puro: tiene lugar como vulnerabilidad social, política y económica. El cuerpo es público, está constituido socialmente en virtud de su exposición a los otros, como sujeto y objeto de deseo y sujeto y objeto de violencia, y su vulnerabilidad depende de la distribución desigual de los recursos

\footnotetext{
49 Butler, J., Dar cuenta de sí mismo, op cit., p. 18.

50 Estos autores aparecen a lo largo de Dar cuenta. de si mismo op. cit.

${ }^{51}$ Butler, J., Dar cuenta de sí mismo, op. cit. Butler incluye, en el capítulo 1, un epígrafe titulado "Interrogantes posthegelianos."

52 Ver, por ejemplo, Butler, J., Vida precaria, op. cit. pp. 13, 46 y 169-170.

53 Ver, por ejemplo, Boladeras, M., (Ed.)., Bioética: justicia y vulnerabilidad, Barcelona, Proteus, 2013, en casos similares los términos "precariedad" y "vulnerabilidad" son sustituidos por otros como "debilidad", "fragilidad", etc.

54 Butler, J., Vida precaria, op. cit. pp. 45 y 52.
} 
económicos, políticos e identitarios. La precariedad y la vulnerabilidad están distribuidas desigualmente. ${ }^{55}$ Finalmente, hay una vulnerabilidad ética: aquella que se me ofrece desde su exposición social y política inevitable como una interpelación por la responsabilidad para con ella: es la precariedad o vulnerabilidad personificada en el rostro del otro. ${ }^{56}$

\section{Sobre metaética deconstructiva}

En ESTE PUNTO ENTRA EN JUEGo LA DiMENSIÓn METAÉTiCA que, como en el caso del inspirador de Butler, Levinas, lo hace bajo la modalidad deconstructiva. Aunque ninguno de los dos la reconozca como tal, en la obra de ambos, sobre todo en la del segundo, dicha metaética opera de forma efectiva, si bien implícita y difusa, lo cual da lugar a interpretaciones diferentes sobre si la reflexión de Levinas es ética normativa o únicamente metaética. ${ }^{57}$ Creo que ambas opciones son compatibles, pero en este punto nos interesa más resaltar la dimensión metaética en su modalidad deconstructiva de un poder exterior que forzara o impusiera la interpelación del otro al yo y la responsabilidad del yo para con el otro. Ni una ni otra son obligatorias o impuestas por un poder exterior a ellas (una realidad o una ley teológica, metafísica u ontológica, etc.). Este es uno de los significados de la precariedad o vulnerabilidad: que la responsabilidad para con el otro puede ser sustituida por la violencia, y viceversa, lo cual introduce a la ética en la ambivalencia o a la ambivalencia en la ética. ${ }^{58}$

J. Derrida, uno de los primeros seguidores de Levinas, trató de salvar la prioridad de la ética frente a un "poder externo" mediante la deconstrucción del mito de una presencia originaria y privilegiada, metafísica u ontológica, que sería el fundamento absoluto y absolutamente verdadero de la significación filosófica. El argumento básico de Derrida consiste en que entre esa (supuesta) presencia originaria y nuestra percepción intuitiva de ella se interpone el lenguaje, oral o escrito, que la expresa si ha de ser comunicada - y que es independiente tanto de la presencia en cuestión como de su perceptor. ${ }^{59}$ Richard Rorty proporciona un refuerzo deconstructivo a

55 Ibid., pp. 52 y 56. Ver, también de la autora, Marcos de Guerra, pp. 15-16.

56 Ibid., pp. 166-169.

${ }^{57}$ La primera opción la defiende Critchley, S., en The Ethics of Deconstruction. Derrida \& Levinas. Blackwell Publishers, 1992, cap. 3. Una síntesis puede verse en Bello Reguera, G., "Jacques Derrida metaética, deconstructiva y ética de la hospitalidad", en Aproximaciones a la filosofía francesa del siglo XX, op. cit. pp. 179-180. La segunda opción es sostenida por Gutting, G., Pensando lo imposible. Filosofia francesa desde 1960, Madrid, Avarogani, 2014, pp. 240 y 266.

${ }^{58}$ El lugar de referencia es Vida precaria, op. cit., pp. 169-170.

59 Bello Reguera, G., "Jacques Derrida metaética, deconstructiva", op. cit., p. 164. 
sostener que no existe un léxico último y único que refleje dicha presencia de forma absolutamente la presencia en cuestión que, en su caso, es la de la naturaleza humana. ${ }^{60}$ La pretensión de que ese léxico existe o debe existir procede del autoritarismo político patriarcal, uno de cuyos elementos básicos es una ética igualmente autoritaria. Frente a ello, la deconstrucción derridiana y rortyana se convierte en metaética deconstructiva a poco que la apliquemos a desmontar la creencia en que esa presencia originaria y privilegiada (idea, esencia, naturaleza, racionalidad, ser, dios, etc.,) "funda" la verdad y la validez absolutas de los juicios morales. De lo cual se infiere que la metaética deconstructiva no sólo deconstruye la ética autoritaria, sino también la metaética correspondiente que, a fin de cuentas, es una política cultural autoritaria. En esta polémica, Derrida y Rorty se sitúan en el lado opuesto de intentos como el de Habermas, sostenido a lo largo de toda su obra, de reconstruir la categoría de validez universal como criterio metaético de aceptabilidad o no aceptabilidad, racionalmente obligatoria, de los juicios morales. ${ }^{61}$

J. Butler, por su parte, imitó a Derrida a la hora de subvertir la identidad - patriarcal - mediante la deconstrucción de la metafísica de la sustancia como "fundamento" de la política patriarcal de género. ${ }^{62}$ Por lo tanto, la metaética deconstructiva implícita en la obra derridiana (y rortyana) lo está también en la suya. Pero ella introduce un elemento que marca una diferencia al sustituir la presencia originaria, metafísica, de Derrida, por la presencia humana originaria o presencia originaria de la humanidad. Entonces, lo que se deconstruye ya no es la presencia metafísica originaria sin más, en su significación abstracta, sino la de la presencia humana ${ }^{63} \mathrm{y}$ su supuesta originariedad, de lo cual se siguen algunas consecuencias decisivas. La primera es que sin una presencia humana originaria no es posible la representación absolutamente verdadera de la humanidad y que, sin esa presencia, no se puede trazar una línea clara y terminante entre esa presencia pura y su ausencia igualmente pura: la no humanidad o inhumanidad impuras. Y la segunda es que la humanidad deconstruida y, por tanto, sin presencia originaria, queda fuera del sistema binario, “.../..." en la variante que le concierne, la oposición humanidad/inhumanidad.

\footnotetext{
${ }_{60}$ Rorty, R., Contingencia, ironía y solidaridad, Barcelona, Paidós, 1991, p. 91.

${ }^{61}$ Sobre su polémica con la filosofía postmoderna, El discurso filosófico de la modernidad. Taurus, Madrid, 1989 cuyas pp. 197-224 están dedicadas a criticar a Derrida. Véase, además, sobre el tema mi texto Azaovagh, A., "La polémica de la diferencia de géneros entre filosofía y literatura a partir de la teoría de actos de habla" en Limites y Fronteras. VV.AA., Tenerife, Facultad de Filosofía de la Universidad de La Laguna, 2009. Entre la abundante recepción crítica de la obra de Habermas, puede verse desde un punto de vista feminista, Palmero Guerra, M. J., Mujer, identidad y reconocimiento. Habermas y la crítica feminista, Santa Cruz de Tenerife, Centro de Estudios de la Mujer de la Universidad de La Laguna, 1998 y "Foucault y los feminismos. Encuentros y desencuentros" en Aproximaciones a la filosofía francesa contemporánea. Deleuze, Foucault, Derrida y Beauvoir op. cit.

${ }^{62}$ Butler, J., El género en disputa, op. cit.

63 Butler, J., Vida precaria, op. cit., pp. 180 y 189.
} 
Butler pone un énfasis especial en destituir la idea misma de una representación verdadera, universal y normativa de la humanidad, aplicada, por si misma, al "nosotros" norteamericano-occidental, que, a la vez, atribuye los "otros" - los "orientales" - el opuesto binario "no humano" o "inhumano". ${ }^{44}$ Sin esa representación normativa de la humanidad, la asociación de las oposiciones binarias humano/ inhumano y nosotros/ellos no está en la realidad, ni en la naturaleza de las cosas; es una construcción cultural autoritaria ya que el constructor político de turno no la discute ni negocia, democráticamente, con el otro, el inhumanizado. Por el contrario, el "nosotros" de turno, utiliza su propia construcción para inducir y legitimar la violencia contra el otro, construido y definido, previamente, como inhumano.

La deconstrucción o rechazo de una representación originaria de la humanidad o "presencia" humana tiene, en el presente contexto, una significación doble. Por un lado, cancela la violencia ética que, a juicio de Butler, consiste en el uso y abuso de la universalidad contra la particularidad y la singularidad ${ }^{65}$, siendo así que la universalidad es una forma o figura de aquella representación. Y, por otro lado, abre la posibilidad de una ética de la no violencia.

\section{Precariedad ética y humanidad precaria.}

Con este Razonamiento De Fondo, Butler pone sobre la mesa filosófica que la humanidad es precaria no sólo en su vida - "vida precaria" - sino también en la representación de sí misma, de su vida, de su presencia y de su identidad. Que esa representación es precaria implica que no es cerrada sobre sí misma, absoluta verdadera e infalible, autoritaria, como en las versiones teológicas o metafísicas, sino abierta a la crítica y al diálogo y, por lo tanto, plural. No se puede hablar de una representación de la humanidad sino de representaciones; ni siquiera de una humanidad sino de humanidades, de lo cual se siguen consecuencias importantes para la ética tanto en su dimensión teórica como aplicada.

En este marco abierto, la ética es redefinida o resignificada por Butler tanto en el conjunto de su matriz teórica como en cada uno de los elementos conceptuales que la integran. Para empezar, la ética se sitúa en la exterioridad del sistema binario de raíz autoritaria y de condición rígida y cerrada, en el que ha sido situada y clausurada tradicionalmente. En esa exterioridad - aunque Butler no lo manifieste

\footnotetext{
${ }^{64}$ Ibid., pp. 176-179.

${ }^{65}$ La expresión "violencia ética" forma parte del subtítulo - "Violencia ética y responsabilidad" - de Dar cuenta de sí mismo op. cit., que, además, vuelve sobre ella en las pp. 15-16 y le dedica el capítulo 2: "Contra la violencia ética."
} 
explícitamente, lo da a entender - la ética no consiste en forzar o imponer, de modo autoritario, una definición única y última, absoluta e infalible de sí misma, frente a otras matrices teóricas como la Política, la Filosofía del lenguaje o la Biología, con las que está entrelazada en la obra de Butler, en la que la interacción entre ellas es omnipresente. Y, si vamos a los elementos conceptuales que la integran su matriz teórica, la situación es análoga. La ética no consiste en imponer definiciones únicas, absolutas y últimas de, por ejemplo, los criterios que usa a la hora de juzgar acciones y situaciones, puesto que no existen presencias originarias o absolutas ni, por tanto, las correspondientes ausencias. En el marco de representaciones plurales de la humanidad no es posible usar una de ellas como criterio normativo absoluto, por parte de un yo o un nosotros concreto y particular - por ejemplo, el norteamericano o el occidental; o el yihadista oriental - en un juicio sobre la humanidad propia y la inhumanidad de los otros para justificar la violencia indiscriminada contra "ellos": "los otros". Por el contrario, las situaciones éticas y políticas, deberían ser abordadas de forma abierta o ambivalente, en la tensión inherente a la decisión que, por lo tanto, nunca debe estar prefabricada como en las éticas tradicionales, surgidas en el espacio imaginario patriarcal y, por lo tanto, irremediablemente autoritarias. ${ }^{66}$ Esa tensión es la entraña misma de la ética que Levinas defiende como prioritaria respecto de la ontología y la epistemología y, al mismo tiempo que defiende la prioridad de la justicia sobre la verdad ${ }^{67}$, de todo lo cual Butler es cómplice.

La misma precariedad inspira la redefinición o resignificación de otras categorías de la ética como la acción o agencia (la conducta o la práctica) y el sujeto o los sujetos implicados en ella. Aquí la ética de la no violencia, de inspiración reciente, se solapa con obra anterior de Butler, más orientada hacia políticas identitarias. Y la clave de este solapamiento es la categoría de performatividad a la que Butler recurre en situaciones y contextos diversos ${ }^{68}$, lo cual sugiere que le confiere una significación omnipresente. Me refiero a que está en el entre-cruce de, por un lado, las diversas representaciones de la humanidad y, por el otro, de la ética y su matriz teórica, así como de cada uno de sus elementos.

La performatividad es, como se sabe bien a estas alturas, una propiedad del lenguaje, en su dimensión pragmática o comunicativa, que consiste en la capacidad de hacer cosas con palabras. Esta capacidad, paradójicamente, constituye uno de los ejemplos más logrados de la precariedad. Es abierta ya que las cosas que "hace" - o "causa" - el lenguaje se sitúan en su exterioridad, por ejemplo, en los interlo-

\footnotetext{
${ }^{66}$ Sobre éticas autoritarias y democráticas ver los trabajos de Bello Reguera, G., citados en las notas 20 y 43.

${ }^{67}$ Levinas, E., Ensayo sobre la exterioridad, op. cit., pp. 70-71 y 104 y ss.

${ }^{68}$ Sobre la performatividad en Judith Butler ver Pérez Navarro, P., Del texto al sexo. Judith Butler y la performatividad, op. cit.
} 
cutores de los actos de habla en los que se expresa o exterioriza. Es ambivalente ya que, según Butler (y otros), puede hacer cosas positivas como la performación de la identidad y cosas negativas como herir a esa misma identidad mediante el lenguaje del odio como son el insulto o el estigma: la humillación. Y es interdependiente, porque cada sujeto lingüístico es comunicativamente insuficiente en sí mismo y dependiente de los otros. Esta interdependencia es la que se expresa o manifiesta en la relación de interpelación/respuesta que Butler ha recogido de contextos teóricos tan diferentes como la filosofía política de Althusser, la teoría de los actos de habla de Austin y, más concretamente, de la ética de la alteridad de Levinas. ${ }^{69}$

En este contexto, Butler sustituye la idea de un "yo" o un "nosotros" cerrado en la totalidad imaginaria de su identidad, indiferente o violento ante la presencia del otro que puede cuestionarle, por un "yo" o un "nosotros" abierto a la interacción o intercomunicación performativa con los otros. Esta apertura interdependiente tiene lugar en la relación de alteridad entre unos y otros, en la que convergen la categoría hegeliana de reconocimiento, de larga data en la obra de Butler ${ }^{70}$, con la levinasiana de responsabilidad, más reciente en sus intereses, pero no menos apreciada o valorada. ${ }^{71} \mathrm{O}$ quizá un poco más, como parece sugerir en Dar cuenta de sí mismo. ${ }^{72}$ Se puede resumir toda esta reflexión sobre la precariedad de la humanidad y, consiguientemente de la ética, a partir de uno de sus rasgos básicos: la interdependencia. En este marco, la agencia o acción moral es inter-acción comunicativa performativa que, como tal, produce efectos en todos los implicados. Entre estos efectos sobresale la inter-subjetivación, la acción y el efecto de hacernos unos a otros sujetos morales caracterizados por el intercambio de agencia o emisión y recepción o paciencia. Por último, no se puede dejar de resaltar que la inter-acción y la inter-subjetivación sólo son expresiones de la inter-humanidad, que hay que diferenciar claramente de la intra-humanidad propia del individualismo autorreflexivo e intrasubjetivo de la tradición idealista y racionalista, así como del comunitarismo cerrado que caracteriza a las sectas religiosas y grupos políticos y culturales que las imitan como los nacionalistas radicales o las culturas autoconsideradas universales

\footnotetext{
${ }^{69}$ Sobre Austin y Althusser ver Butler, J., Lenguaje, poder e identidad, op. cit., pp. 49 y ss. Sobre Levinas puede consultarse Azaovagh, A., "La intersubjetivación como responsabilidad asimétrica" en Femenías, M.L. y Casale, R., Judith Butler fuera de sí. Espectros, diálogos y referentes polémicos, Rosario, Prohistoria, 2017, pp. 31-46.

${ }^{70}$ Ver, al respecto, Butler, J., Sujetos del deseo. Reflexiones hegelianas en la Francia del siglo XX, Buenos Aires, Amorrortu, 2012.

${ }^{71}$ Vease mi texto Azaovagh, A., "La intersubjetivación como responsabilidad asimétrica” en Femenías, M.L. y Casale, R., Judith Butler fuera de sí. Espectros, diálogos y referentes polémicos, Rosario, Prohistoria, 2017, pp. 31-46.

${ }^{72}$ En Hassen, B., "The Ethics of the Other", op.cit., puede verse un relato similar al de Butler del paralelismo Hegel/Levinas.
} 
y, por lo tanto, omniinclusivas. En mi opinión, el término inter-humanidad, ${ }^{73}$ con su significación irremediablemente abierta, traduce bien el párrafo final de Vida Precaria:

"Si las humanidades tienen algún futuro como crítica cultural y si la crítica cultural tiene hoy alguna tarea, es sin duda la de devolvernos a lo humano allí donde no esperamos hallarlo, en su fragilidad, en su fragilidad y en el límite de su capacidad de tener algún sentido. Tenemos que interrogar la emergencia delo humano en el límite de lo que podemos pensar, lo que podemos escuchar, lo que podemos ver, lo que podemos sentir.

Esto podría inducirnos afectivamente a revigorizar el proyecto intelectual de criticar, cuestionar, llegar a entender las dificultades y las exigencias de la traducción cultural y el disenso, creando un sentido de lo público en el que las voces opositoras no sean intimidadas, degradas o despreciadas, sino valoradas como impulsoras de una democracia más sensible - un rol que ocasionalmente desempeñan." 74

\footnotetext{
73 Tomo este término del trabajo de Bello Reguera, G., "Diferencia negativa, alteridad e interhumnanidad", en Quiles, M. N., y otros, (eds.). Psicología de la maldad. Cómo todos podemos ser Caín, Madrid, Grupo 5, 2014. Por su parte, el autor atribuye su uso inicial a Levinas.

${ }^{74}$ Butler, J., Vida precaria, op cit, p. 187.
} 


\section{Referencias Bibliográficas}

Adorno, Theodor, Dialéctica de la ilustración, Madrid, Akal, 2007.

Adorno, Theodor, Minima moralia, Madrid, Taurus, 1984

Adorno, Theodor, Problems of Moral Philosophy. Trad. Rodney Livingstone, Stanford, Stanford University Prees, 2001.

Azaovagh, Anisa, "La intersubjetivación como responsabilidad asimétrica" en Femenías, M.L. y Casale, R., Judith Butler fuera de sí. Espectros, diálogos y referentes polémicos, Rosario, Prohistoria, 2017.

Azaovagh, Anisa, "La polémica de la diferencia de géneros entre filosofía y literatura a partir de la teoría de actos de habla" en Limites y Fronteras", VV.AA., Tenerife, Facultad de Filosofía de la Universidad de La Laguna, 2009.

Bello Reguera, Gabriel, "Diferencia negativa, alteridad e interhumnanidad", en Quiles, Ma . Nieves y otros, (eds.), Psicología de la maldad. Cómo todos podemos ser Caín, Madrid, Grupo 5, 2014.

Bello Reguera, Gabriel, “¿Ética filosófica o ciencia del bien y del mal? La matriz Araguren y otras claves de la filosofía española”, en revista Claves de la razón práctica. n 197, Madrid, 2009.

Bello Reguera, Gabriel, "Jacques Derrida. Metaética deconstructiva y ética de la hospitalidad”, en Fernández Agis, Domingo y Sierra González, Angela, (eds.). Aproximaciones a la filosofía francesa contemporánea. Deleuze, Foucault, Derrida y Beauvoir. Barcelona, Laertes, 2007.

Bello Reguera, Gabriel, "Pragmática, hermenéutica y ética de la alteridad", en Ońate, Teresa y otros (eds.), Crítica y crisis de Occidente. Al encuentro de las interpretaciones, Madrid, Dykinson, S.L, 2013.

Bello Reguera, Gabriel, El valor de los otros. Más allá de la violencia intercultural, Madrid, Biblioteca Nueva, 2006.

Bocardo Crespo, Enrique, La politica del negocio. Cómo la administración Bush vendió la guerra de Irak, Barcelona, Horsori, 2012.

Boladeras, Margarita (Ed.), Bioética: justicia y vulnerabilidad, Barcelona, Proteus, 2013.

Burgos, Elvira, Qué cuenta como una vida. La pregunta por la libertad en Judith Butler, Madrid, Mínimo tránsito, 2008. 
Butler, Judith, Cuerpos que importan. Sobre los limites materiales y discursivos del «sexo", Buenos Aires, Paidós, 2002.

Butler, Judith, Dar cuenta de sí mismo. Violencia ética y responsabilidad, Buenos Aires, Amorrortu, 2009.

Butler, Judith, Deshacer el Género, Barcelona, Paidós, 2006.

Butler, Judith, El género en disputa. El feminismo y la subversión de la identidad, Barcelona, Paidós, 2007.

Butler, Judith, "Ethical ambivalence", en Garber, Majorie, Hassen, Beatrice y Walkowitz, Rebecca, (Eds.), The Turn to Ethics, Nueva York Routledge, Nueva York, 2000.

Butler, Judith, Lenguaje, poder e identidad, Madrid, Síntesis, 2004.

Butler, Judith, Sujetos del deseo. Reflexiones hegelianas en la Francia del siglo XX, Buenos Aires, Amorrortu, 2012.

Butler, Judith, Marcos de guerra. Las vidas lloradas, Barcelona, Paidós,2010.

Butler, Judith, Vida precaria. El poder del duelo y la violencia, Buenos Aires, Paidós, 2006.

Butler, Judith, Violencia de Estado, guerra, resistencia. Por una nueva politica de izquierdas Madrid, Katz, 2011.

Cavarero, Adriana, Horrorismo: Nombrando la violencia contemporánea, Barcelona, Anthopos, 2009.

Conill, Jesús, "El carácter hermenéutico y deliberativo de las éticas aplicadas" en Cortina, A., y García Marzá, D., (Eds), Razón pública y éticas aplicadas. Los caminos de la razón práctica en una sociedad pluralista, Madrid, Tecnos, 2003.

Cortina, Adela, Ética aplicada y democracia radical, Madrid, Tecnos, 1993.

Critchle, Simon. The Ethics of Deconstruction. Derrida \& Levinas, Blackwell Publishers, 1992.

Femenías, María Luisa, "Butler, la muerte del hombre y el sujeto opaco". Revista de Psicoanálisis”, en revista Psicoanálisis, Tomo LXXI, nº 2/3, Argentina, 2013.

Gómez, Carlos y Muguerza, Javier, (eds), La aventura de la moralidad. Paradigmas, fronteras y problemas de la ética, Madrid, Alianza Universidad, 2007. 
Gutting, Gary, Pensando lo imposible. Filosofía francesa desde 1960, Madrid, Avarogani, 2014.

Hassen, Beatrice, "The Ethics of the Other", en Garber, Majorie, Hassen, Beatrice y Walkowitz, Rebecca, (Eds.). The Turn to Ethics. Routledge, Nueva York, 2000.

Martin Rojo, Luisa, "El campo de batalla de los discursos. Discursos e imágenes en torno a la ocupación de Irak" en Roldán, Concha, Ausín, Txetxu., Mate, Reyes, (eds), Guerra y Paz en nombre de la política, Madrid Calamar, 2004.

Levinas, Enmanuel. Totalidad e infinito. Ensayo sobre la exterioridad, Salamanca, Sígueme, 2001.

López de la Vieja, Teresa, La pendiente resbaladiza. La práctica de la argumentación moral, Madrid, Plaza y Valdés, 2010.

Rorty, Richard, Contingencia, ironía y solidaridad, Barcelona, Paidós,1991.

Palmero Guerra, Ma José, "Foucault y los feminismos. Encuentros y desencuentros", en Aproximaciones a la filosofía francesa contemporánea. Deleuze, Foucault, Derrida y Beauvoir, Barcelona, Laertes, 2007.

Palmero Guerra, $\mathrm{M}^{\mathrm{a}}$ José. Mujer, identidad y reconocimiento. Habermas y la crítica feminista, santa Cruz de Tenerife, Centro de Estudios de la Mujer de la Universidad de La Laguna, 1998.

Pérez Navarro, Pablo, Del texto al sexo Judith Butler y la performatividad, Madrid, Egales, 2008.

Rodríguez Arnáiz, Graciano Interculturalidad y convivencia. El "giro intercultural" de la filosofía, Madrid, Biblioteca Nueva, 2008.

Stevenson, Charles. Ética y lenguaje, Buenos Aires, Paidós, 1971.

DOI: https://doi.org/10.15366/bp2019.22.007

Bajo Palabra. II Época. № 22. Pgs: 147-170 